\title{
Mobility of trace metals in freshwater sediments by coupling solid-liquid exchanges, biogeochemical reactions and interstitial diffusion
}

\author{
V. Devallois ${ }^{1,2}$, P. Boyer ${ }^{1}$, J.-L. Boudenne ${ }^{2}$ and B. Coulomb ${ }^{2}$

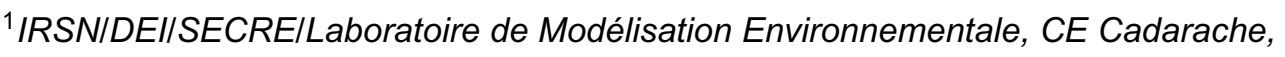 \\ 13115 Saint Paul-lez-Durance, France \\ ${ }^{2}$ Universités d'Aix-Marseille I, II, III - CNRS, Laboratoire Chimie Provence - UMR 6264, \\ Équipe «Chimie de l'Environnement Continental», 3 place Victor Hugo, case 29, \\ 13331 Marseille, France
}

\begin{abstract}
Sediments may act as a sink for nutrients and trace metals after deposition. It may pose a risk for surface water quality and ecosystem health when environmental changes lead to release nutrients and trace metals stored in these sedimentary stocks. The management of the quality of freshwater systems needs to understand the processes of remobilisation of these stocks. This mobility is dependent on the erosion, on the interstitial diffusion of the mobile phases and on the bioturbation. These mechanisms depend on early diagenetic processes that condition the physical and biogeochemical properties of the sedimentary column. These properties are mainly influenced by the redox transformations resulting from oxidation of the organic matter by the microbial activity. These reactions generate vertical profiles of nutrient and metals concentrations along the sedimentary column. This paper aims to propose a modelling and an experimental protocol to determine vertical profiles of nutrients and trace metals in saturated sedimentary columns of freshwater systems. The modelling approach is based on a coupling between bio-geochemical processes [1], interstitial diffusion [2,3] and solid-liquid exchanges. The main originality of the model is the $\mathrm{pH}$ determination that is directly calculated from the pore water concentrations of the ionic species. As illustration, this paper presents an application to natural sediment cores collected in the Durance Rivers.
\end{abstract}

In freshwater systems, trace metal pollutants are transferred into water and sedimentary columns under dissolved forms and fixed onto solid particles. Accumulated in the sedimentary areas, these latter ones can constitute important stocks of materials and associated pollutants. The mobility of the stocks of pollutants is mainly depending on the erosion, on the interstitial diffusion of the mobile phases (dissolved and colloidal) and on the bioturbation. In this context, this communication presents an analysis of the mobility by interstitial diffusion by comparing experimental results and modelling. This topic involves two main points: 1) Trace metal fractionation between their mobile (dissolved and colloidal) and non mobile (fixed onto the particles) forms; 2) Interstitial diffusion of the mobile phases. The first point is governed by sorption/desorption processes at the particle surfaces. In the sedimentary column, these processes are regulated by physico-chemical parameters as $\mathrm{pH}$, potential redox, concentrations and nature of particles. In sediments, these parameters are mainly influenced by biochemical reactions resulting from the oxidation of the organic matter by the microbial activity: oxic respiration, denitrification, manganese hydroxide and iron hydroxide reduction, sulphate reduction, methanogenesis [4]. In this context, this work proposes a model coupling these biogeochemical reactions to sorption/desorption processes of trace metals and interstitial diffusion. In order to refine and to evaluate this model, an experimental protocol has also been developed to obtain the vertical distributions of the predominant physico-chemical parameters and solid-liquid fractionations of metals (Fe, Mn, Co, $\mathrm{Cu}, \mathrm{Ni}, \mathrm{Pb}, \mathrm{Zn}$ ) in natural sediment cores. The first comparisons realised on cores collected in the Durance and Rhône rivers allows to identify the gaps and the efficiencies of the modelling approach. 


\section{MODELLING}

The aim of the modelling is to provide a tool to analyse, understand and reproduce the vertical evolutions of chemical conditions along a saturated sedimentary column. These conditions are mainly characterized by dissolved $\mathrm{O}_{2}$ concentration, nutrient concentrations and $\mathrm{pH}$ conditions in pore water. The variables are the concentrations of 18 chemical species considered as a function of three potential phases (particulate (P), dissolved (D) and colloidal (C)) and as a function of the depth (z) and the time (t). For each species, the particulate phase corresponds to fractions adsorbed onto the solid particles (diameter $>0,45 \mu \mathrm{m}$ ) of the sediment and to species constituent of the sediment or precipitated. About the non particulate fractions, the colloidal phase is susceptible to absorb trace metals and the dissolved phase is non reactive to trace metals.

The vertical variations of these variables along a sedimentary column are mainly dependent on the biogeochemistry of early diagenesis and interstitial diffusion of mobile phases (dissolved and colloidal). Consequently, the modelling proposed in this paper applies a chain of four models: 1) Interstitial diffusion of the mobile phases, 2) biogeochemical reactions, 3) evolution of $\mathrm{pH}$ in the sedimentary column and 4) solid-liquid fractionation of trace metals in the sedimentary column.

\subsection{Interstitial diffusion}

The interstitial diffusion along the sedimentary column concerns the dissolved and the colloidal forms of the biogeochemical and trace metals species. This process is described by the first Fick's law. The coefficient of interstitial diffusion is given [5, 6]:

$$
D_{\text {sed }}(z)=\frac{D_{s w}}{1-\ln \left(n(z)^{2}\right)}
$$

In this relation $D_{s w}\left(\mathrm{~m}^{2} \cdot \mathrm{s}^{-1}\right)$ is the coefficient of molecular diffusion in water and $n(z)$ is the porosity, which is given in our case by the calibration of the Athy's relation [5] on the experimental data.

\subsection{Biogeochemical reactions}

The aim of the biogeochemical model is to provide the vertical variations of the different forms of the chemical species along the sedimentary column. The reactions are modelled according the approaches developed by Wang and Van Cappellen [1, 7, 8]. It considers the primary reactions of organic matter oxidation (aerobic respiration, denitrification, Mn oxide reduction, Fe oxide reduction and sulphate reduction) and the secondary reactions that are the precipitation of carbonate and sulphide phases with dissolved $\mathrm{Fe}$ and $\mathrm{Mn}$ and the eventual re-oxidation by $\mathrm{O}_{2}$. In our case, the model has been completed with the geochemical processes of calcite dissolution. For the primary reactions, the kinetic are based on Michaelis-Menten kinetics: the rate of each degradation pathway is not only depending from the reactivity of organic matter but also from the availability of the electron acceptor [7]. For the secondary reactions, bi-molecular reaction rate laws are used to describe the reactions kinetics $[1,9,10]$.

\subsection{Evolution of pH}

$\mathrm{pH}$ is required to determine the trace metal fractionation between their dissolved and particulate forms. Contrary to Wijsman et al. (2001), $\mathrm{pH}$ is not here considered as a forced function. It is calculated from the ionic species concentrations issues from the resolution of the biogeochemical reactions previously described. From these concentrations, $\mathrm{pH}$ is determined by considering acido-basic equilibrium, mass conservation and electroneutrality. 


\subsection{Solid-liquid exchanges of trace metals}

The modelling of the solid-liquid exchanges is performed for five trace metals: $\mathrm{Co}, \mathrm{Cu}, \mathrm{Ni}, \mathrm{Pb}, \mathrm{Zn}$. The approach considers, for each metal, five fractions: dissolved and adsorbed 1) on clays, 2) on precipitates of carbonates, 3) on sulphide, 4) on organic matter and 5) on Fe and Mn oxides under their colloidal and particulate forms. The mechanisms taken into account to model the exchanges are ionic exchanges for clay, coprecipitation for precipitates of carbonates and sulphides and adsorption-desorption for organic matter and $\mathrm{Fe}$ and $\mathrm{Mn}$ oxides. These mechanisms are depending on the trace metals and particles couples, on the behaviour of the chemical species and on the $\mathrm{pH}$, these two last parameters being deduced from the resolution of the biogeochemical model. The main hypothesis is that these processes are faster than the biogeochemical reactions and the interstitial diffusion. Consequently, they can be considered at the equilibrium. The model is currently developed and calibrated from the experiments and more precisely from the results of the sequential extractions.

\section{EXPERIMENTAL METHOD}

The relevance of the modelling approach is determined by confrontations with empirical data. Achieve this one must be applied an experimental protocol, able to measure the vertical distributions of the main physicochemical parameters and of the solid-liquid fractionations of metals along cores of natural sediments. This experimental protocol is divided in four parts: 1) Sampling of natural sediment cores in rivers, 2) Analysis of the vertical profiles of $\mathrm{pH}$, redox and dissolved $\mathrm{O}_{2}$ with microsensor, 3) Under nitrogen-saturated atmosphere, vertical sectioning of the cores and separation of pore water and solid sediment of each layer, 4) Analysis of each phase: organic matter (TOC analyser), nutriments (High Performance Ionic Chromatography), metal contents (ICP-AES), grain size distributions (size analyser), density of the solid matter, water contents and porosity.

\section{APPLICATIONS TO DURANCE RIVER SAMPLES}

As illustration, this paper presents an application of the model and of the experimental protocol to natural sediment cores collected in the Durance River in July 2007.

\subsection{Profiles of dissolved oxygen and $\mathrm{pH}$}

The profile of dissolved $\mathrm{O}_{2}$ (Figure 1) shows that concentration of dissolved $\mathrm{O}_{2}$ decreases strongly from the first millimetres of depth. The sediment becomes totally anoxic at 1 centimetre of depth. The model provides correct agreements and shows that this decrease results from the aerobic respiration of bacteria. In the same time, $\mathrm{pH}$ decreases slowly with the depth with a global variation of $\Delta \mathrm{pH}=1$. The most intense decrease of $\mathrm{pH}$ is concentrated in the uppermost 2 centimetres of the sediments where the oxygen
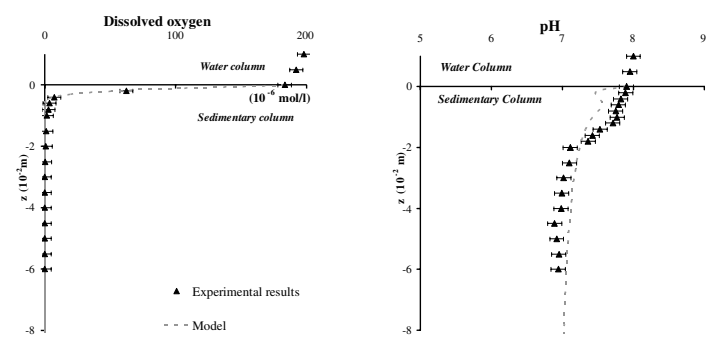

Figure 1. Profiles of dissolved oxygen and pH, July 2007. 

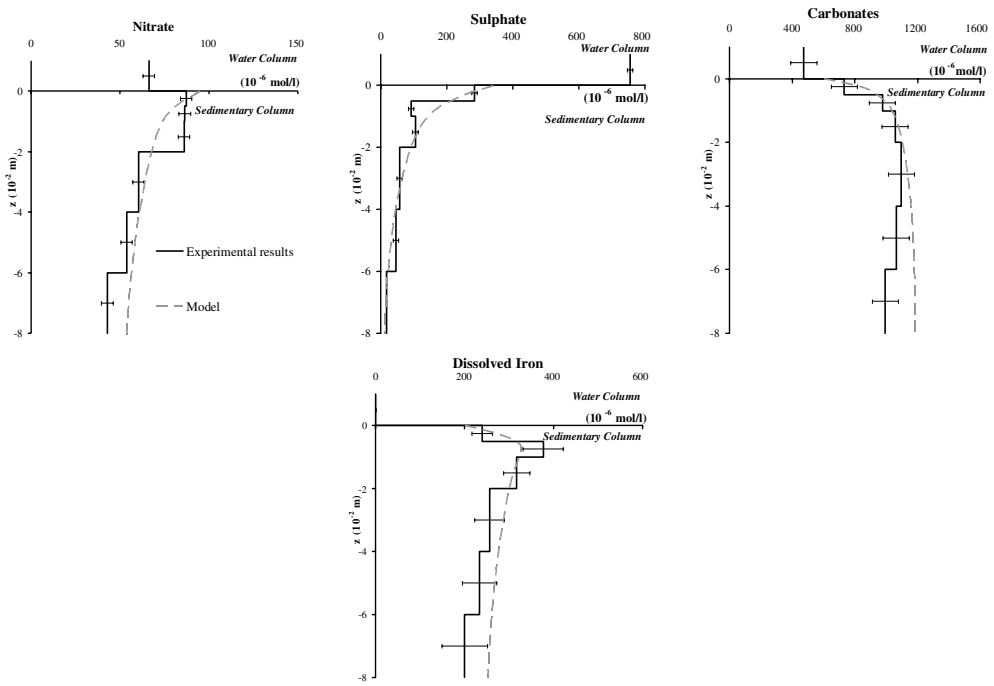

Figure 2. Profiles of nutrients, July 2007.

is consumed by aerobic respiration. This reaction produces $\mathrm{H}^{+}$ions and decreases $\mathrm{pH}$. This behaviour is correctly reproduced by the model, which shows that other biogeochemical reactions like nitrate and sulphate reduction, oxidation by $\mathrm{O}_{2}$ take place at this depth interval and produce $\mathrm{H}^{+}$ions. The only biogeochemical reactions responsible of consumption of $\mathrm{H}^{+}$ions are calcite dissolution and manganese and iron oxide reduction. Above two centimetres, $\mathrm{pH}$ variations become quasi null and are well fitted by the model.

\subsection{Profiles of nutrients}

The changes of $\mathrm{O}_{2}$ and $\mathrm{pH}$ are associated to the vertical evolutions of nutrients like nitrates, sulphates and carbonates. The experimental profiles of nitrates and sulphates show that their concentrations decrease in the sedimentary column. The model associates this behaviour to the denitrification and to the sulphate reduction. Concerning the carbonate ions, the increasing of their concentrations during the first centimetres is the result of the organic matter oxidation and calcite dissolution. From $2 \mathrm{~cm}$, the decreasing of these concentrations is due to the precipitation of carbonate ions with dissolved manganese and iron resulting of their oxide reduction. Dissolved manganese and iron concentration increase in the first centimetres $(0.5-1 \mathrm{~cm})$. In the model, this is resulting from manganese and iron oxide reduction. Below 2 centimetres, the concentrations of dissolved manganese and iron begin to decrease. The model attributes this result to the dissolved manganese and iron release in the porewater. They can then precipitate with dissolved species like carbonate or/and sulphur ions. The behaviours of iron and manganese are well reproduced by the model. This is an interesting result because, under their oxide form, iron and manganese ions are known to behave like "trace metals scavengers", principally for $\mathrm{Co}, \mathrm{Cu}, \mathrm{Ni}, \mathrm{Pb}$ and $\mathrm{Zn}$.

\subsection{Behaviour of trace metals in the sedimentary column}

Concerning the behaviour of studied trace metals, it is interested to show specifically the profiles of nickel and of cobalt because their analogous radionuclides ${ }^{63} \mathrm{Ni},{ }^{58} \mathrm{Co}$ and ${ }^{60} \mathrm{Co}$ are present in the liquid effluent of nuclear plants. Sequential extraction results (Figure 3) show that Ni is principally associated with iron and manganese oxides. Moreover, dissolved $\mathrm{Ni}$ has the same trend profiles of dissolved iron 
and manganese. So, the behaviour of $\mathrm{Ni}$ depend on the iron and manganese oxides: in oxic zone, $\mathrm{Ni}$ is fixed into manganese and iron oxides; in anoxic zone, oxides are reduced and released the trace metals, $\mathrm{Ni}$ can then diffuse into the oxic zone where it can be resorbed onto the particles and/or precipitate with sulphides.
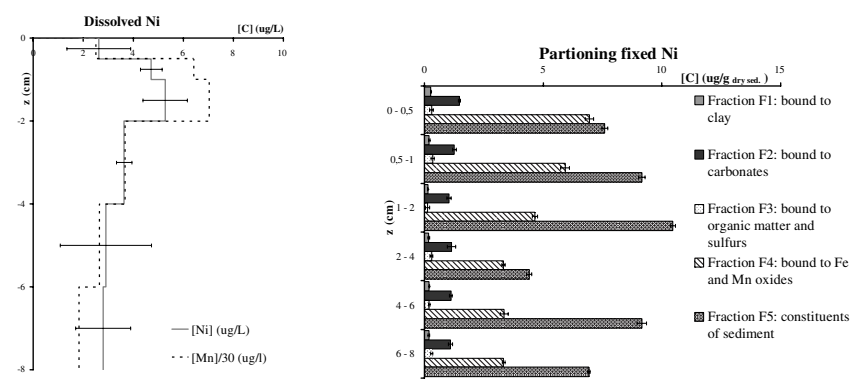

Figure 3. Behaviour of Ni in the sedimentary column, July 2007.
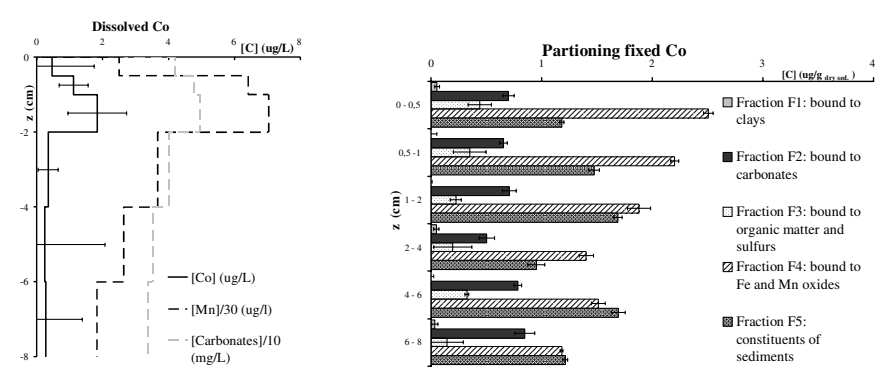

Figure 4. Behaviour of Co in the sedimentary column, July 2007.

Fixed Co is principally associated with oxides like Ni but also with carbonates. The profile of dissolved Co has the same trend as manganese and carbonate ions. So, the behaviour of Co is depending on manganese and carbonate ions.

At the image of nickel and cobalt, these results show that the transfers of trace metals in sediments are principally associated to the behaviours of $\mathrm{Mn}$ and Fe oxides and carbonated and sulphide phases. This highlights the interest of a coupling with biogeochemical and interstitial diffusion models. At the current stage of this work, these experimental results allow us to determine the main processes of liquidsolid exchange for each studied trace metals and to calibrate the modelling of these exchanges as a function of the considered fractions (clay, organic matters, carbonate, suphide and Fe and Mn oxides).

\section{CONCLUSIONS}

A modelling and an experimental protocol dedicated to assess the behaviour of trace metals in saturated sedimentary columns of freshwater systems are still in a step of development. The modelling is based on a coupling between biogeochemical processes [7], interstitial diffusion [2, 3] and solid-liquid exchanges. The main originality is the $\mathrm{pH}$ determination that is directly calculated from the pore water concentrations of the ionic species and the coupling between biogeochemical processes and solid-liquid exchanges.

To illustrate the general behaviour of this model, the paper presents an application to natural sediment cores collected in the Durance river (south-east of France) in July 2007. The results show 
that the model provides good agreements with the experimental profiles of the biogeochemical species. For trace metals, the experimental results highlight the importance of this biogeochemical species; they allow us to calibrate the mechanisms of interaction with the different solid fractions ( $\mathrm{Fe}$ and $\mathrm{Mn}$ oxides, organic matters, carbonates, sulphides and clays). From these results, the next step of these developments is the achievement of the modelling of solid-liquid fractionation of trace metals $(\mathrm{Co}, \mathrm{Cu}, \mathrm{Ni}, \mathrm{Pb}, \mathrm{Zn})$.

In practice, this global approach appears as a useful tool to interpret the chemical properties of sediments. The objective is a better understanding of these transfers to guide management efforts to improve water quality and hydrosystem health. In this context, a simplest version will be deduced and linked to more complete water quality model including hydraulic and sedimentary models.

\section{Acknowledgments}

The authors gratefully thank Mr Laurent Vassalo for conducting the ICP-AES measurements. The IRSN (Institut de Radioprotection et de Sureté Nucléaire) and the CNRS National Network ERICHE (Evaluer et Reduire l'Impact de la CHimie sur l'Environnement) has financially supported this research as well.

\section{References}

[1] Wang Y. and Van Cappellen P. A multicomponent reactive transport model of early diagenesis: Application to redox cycling in coastal marine sediments. Geochimica et Cosmochimica Acta (1996); 60 (16): 2993-3014.

[2] Boudreau B.P. The diffusive tortuosity of fine-grained unlithified sediments. Geochimica et Cosmochimica Acta (1996); 60 (16): 3139-42.

[3] Boudreau B.P. A method-of-lines code for carbon and nutrient diagenesis in aquatic sediments. Computers and Geosciences (1996); 22 (5): 479-96.

[4] Froelich P.N., Klinkhammer G.P., Bender M.L., Luedtke N.A., Heath G.R., Cullen D., Dauphin P., Hammond B. and Maynard V. Early oxidation of organic matter in pelagic sediments of eastern equatorial Atlantic: Suboxic diagenesis. Geochimica et Cosmochimica Acta (1979); 43: 1075-90.

[5] Boudreau B.P. Diagenetic Models and Their Implementation - Modelling Transport and Reactions in Aquatic Sediments -, Springer ed., (1997) 414 pp.

[6] Boudreau B.P. Metals and models: Diagenetic modelling in freshwater lacustrine sediments. Journal of Paleolimnology (1999); 22: 227-51.

[7] Van Cappellen P. and Wang Y. Reactive transport modeling of redox chemistry in aquatic sediments: implications for trace metal distributions. ACS Division of Environmental Chemistry (1997); 37 (1): 134-36.

[8] Wijsman J.W.M. Early diagenetic processes in northwestern Black Sea sediments: Netherlands Institute of Ecology (University Groningen), Centre for Estuarine and Coastal Ecology (2001) $121 \mathrm{pp}$.

[9] Rickard D. The solubility of FeS. Geochimica et Cosmochimica Acta (2006); 70: 5779-89.

[10] Rickard D. and Luther III G.W. Kinetics of pyrite formation by the HS oxidation of iron (III) monosulphide in aqueous solutions between 25 and $125^{\circ} \mathrm{C}$ : The mechanism. Geochimica et Cosmochimica Acta (1997); 61 (1): 135-47. 